\title{
PEI government announces catastrophic drug plan
}

$\mathrm{O}$ ne of the last two provinces without a catastrophic drug plan will get one later this year, according to a surprise announcement by the Prince Edward Island government. The plan will have no ceiling and will cover all prescription drugs in the provincial formulary.

"This program will allow us to provide coverage for almost every prescription medication recommended by the National Common Review Plan and the Pan-Canadian Oncology Drug Review Plan," said Health and Wellness Minister Doug Currie. He says he believes the plan is the strongest in Atlantic Canada and compares to the best in the rest of Canada. It will take effect on Oct. 1.

Given that more than a quarter of Islanders do not have private health insurance, the plan is designed to ensure that yearly prescription drug costs don't cripple a family's finances. Together the High Cost Drug Program and the new Catastrophic Drug Program will result in $\$ 8.2$ million in provincial funding to support Islanders who need prescription medications.

The new catastrophic program and the existing highcost drug program will cost the province an estimated $\$ 8.2$ million annually.

"The goal of the program is to protect any individual or family whose drug costs are consuming an unreasonable share of their income, be it from a combined cost of using drugs for several common diseases, or one extremely high-cost drug for a less common or rare disease," said Premier Robert Ghiz at the May 10th event announcing the program. "People shouldn't have to choose between buying groceries or getting their prescription filled. Placing a cap on out-

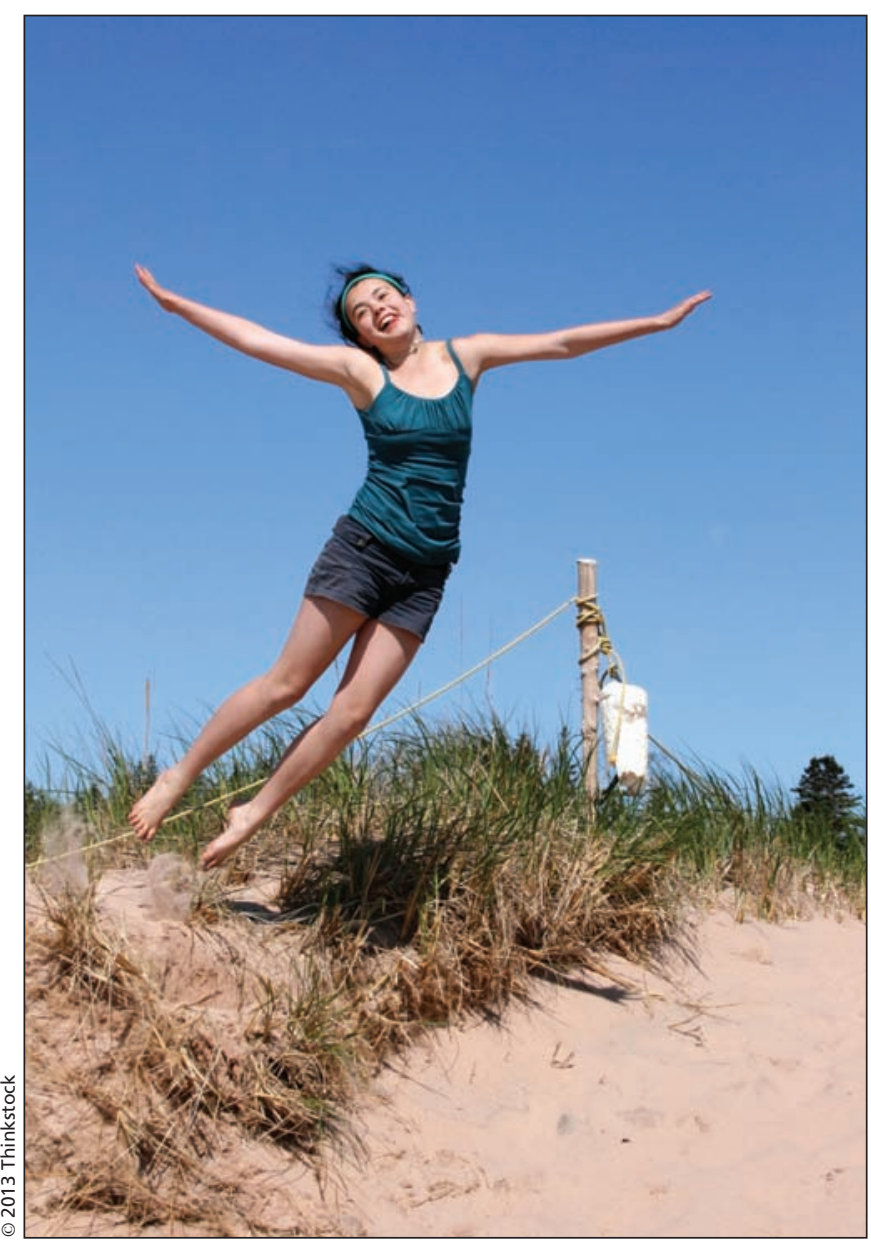

As of Oct. 1, Prince Edward Islanders will have a catastrophic drug plan to protect individuals and families whose drug costs are consuming an unreasonable share of their income.

of-pocket prescription drug costs will ensure every Islander has access to the medications they require."

The coverage depends on the percentage of family income spent on drugs. A family with an income of less than \$20 000 annually will pay for prescriptions out-of-pocket until their drug costs reach $3 \%$ of the family income, at which point the plan will kick in. This goes up to $5 \%$ for those with an income between $\$ 20000$ and $\$ 50000$ and 8\% for a family with income between $\$ 50000$ and $\$ 100000$. Those earning more than $\$ 100000$ will get their prescriptions paid for after their drug bill reaches $12 \%$. About 6000 Islanders will benefit from the program.

The announcement was welcomed by the network of health charities in the province that have been campaigning for years for a catastrophic drug plan, but caught everyone by surprise since there had been no mention of it in the spring budget.

Lori Barker, the executive director of the Canadian Cancer Society in PEI said she was "absolutely surprised and thrilled," by the announcement. "It's been a long time coming and the government has had the benefit of learning from experiences in other provinces. This plan means the support will be there relative to household income."

When asked why the province can afford to implement the plan in October when there was no money at budget time, Ghiz credited the recent savings in generic drug costs along with moving some money around within the health portfolio.

There are still questions around exactly how the plan will be administered, but the government says the fine tuning will be done in the coming months. It will also set up an expert committee to ensure an evidence -based approach to benefit coverage. - Karen Birchard, Charlottetown, Prince Edward Island

CMAJ 2013. DOI:10.1503/cmaj.109-4513 